\title{
A COMPREENSÃO LEITORA E O TEXTO EXPOSITIVO
}

\author{
Juliana Regiani Pereira \\ Luciane Baretta
}

Submetido em 29 de maio de 2018.

Aceito para publicação em 22 de setembro de 2018.

Cadernos do IL, Porto Alegre, n. ${ }^{\circ}$ 56, mês de novembro. p. 213-228

\section{POLÍTICA DE DIREITO AUTORAL}

Autores que publicam nesta revista concordam com os seguintes termos:

(a) Os autores mantêm os direitos autorais e concedem à revista o direito de primeira publicação, com o trabalho simultaneamente licenciado sob a Creative Commons Attribution License, permitindo o compartilhamento do trabalho com reconhecimento da autoria do trabalho e publicação inicial nesta revista.

(b) Os autores têm autorização para assumir contratos adicionais separadamente, para distribuição não exclusiva da versão do trabalho publicada nesta revista (ex.: publicar em repositório institucional ou como capítulo de livro), com reconhecimento de autoria e publicação inicial nesta revista.

(c) Os autores têm permissão e são estimulados a publicar e distribuir seu trabalho online (ex.: em repositórios institucionais ou na sua página pessoal) a qualquer ponto antes ou durante o processo editorial, já que isso pode gerar alterações produtivas, bem como aumentar o impacto e a citação do trabalho publicado.

(d) Os autores estão conscientes de que a revista não se responsabiliza pela solicitação ou pelo pagamento de direitos autorais referentes às imagens incorporadas ao artigo. A obtenção de autorização para a publicação de imagens, de autoria do próprio autor do artigo ou de terceiros, é de responsabilidade do autor. Por esta razão, para todos os artigos que contenham imagens, o autor deve ter uma autorização do uso da imagem, sem qualquer ônus financeiro para os Cadernos do IL.

\section{POLÍTICA DE ACESSO LIVRE}

Esta revista oferece acesso livre imediato ao seu conteúdo, seguindo o princípio de que disponibilizar gratuitamente o conhecimento científico ao público proporciona sua democratização.

http://seer.ufrgs.br/cadernosdoil/index

Quinta-feira, 22 de novembro de 2018. 


\title{
A COMPREENSÃO LEITORA E O TEXTO EXPOSITIVO
}

\section{READING COMPREHENSION AND THE EXPOSITORY TEXT}

\author{
Juliana Regiani Pereira* \\ Luciane Baretta**
}

\begin{abstract}
RESUMO: A leitura se inicia na decodificação, passa à compreensão literal, inferencial, indo até à compreensão textual profunda. Os professores de línguas possuem papel fundamental no ensino de estratégias para que seus alunos se tornem leitores proficientes. Textos expositivos são importantes na construção da criticidade dos alunos, pois trazem informações que instigam a sua reflexão, pois, normalmente, estão mais acostumados a ler textos narrativos, na escola e no cotidiano. O objetivo deste artigo é fazer uma revisão de literatura com vistas a refletir sobre a relevância do ensino da compreensão leitora de textos expositivos para que os alunos alcancem proficiência e se tornem cidadãos críticos, apresentando o reconto oral como uma possibilidade de instrumento de avaliação da compreensão do texto expositivo.
\end{abstract}

PALAVRAS-CHAVE: leitura; compreensão leitora; textos expositivos; reconto oral.

ABSTRACT: The act of reading involves different processes, such as decoding, literal and inferential comprehension until comprehension is achieved. Language teachers have a fundamental role in the teaching of strategies so as students become proficient readers. Expository texts are important pieces in the construction of this proficient reader, for they present information that motivates students' reflections, who are often more used to read narratives in and out of school. The aim of this paper is to review the literature to reflect upon the importance of teaching how to read expository texts so as students become proficient readers and critical citizens. The task of retelling is suggested as a possibility of evaluation of the reading comprehension of expository texts.

KEYWORDS: reading; reading comprehension; expository texts; oral retelling.

\section{Introdução ${ }^{1}$}

Ler é um processo complexo que compreende desde a decodificação de letras até a compreensão plena de um texto e, em cada leitor, existe uma precisa e eficaz mecânica neuronal (DEHAENE, 2012). O processo de leitura começa a partir da decodificação das letras por meio do aprendizado do alfabeto, porém, não termina no momento em que um indivíduo é alfabetizado, já que ler não é apenas o ato de decodificar (SCLIAR-CABRAL, 2015; MORAIS, 2013; DEHAENE, 2012; SOUZA,

\footnotetext{
${ }^{*}$ Mestranda em Letras pela Universidade Estadual do Centro-Oeste - UNICENTRO, bolsista CAPES, juli_re_pe@yahoo.com.br

Professora do Departamento de Letras e do Programa de Pós-Graduação em Letras - Interfaces entre Língua e Literatura, na Universidade Estadual do Centro-Oeste - UNICENTRO, Doutora em Língua Inglesa e Linguística Aplicada pela Universidade Federal de Santa Catarina - UFSC, barettaluciane@gmail.com

${ }^{1}$ O presente trabalho foi realizado com apoio da Coordenação de Aperfeiçoamento de Pessoal de Nível Superior - Brasil (CAPES) - Código de Financiamento 001.
} 
2012; SMITH, 1989). Flôres (2008) explica que uma comprovação de que o ato de ler não está reduzido apenas à decodificação, dá-se pelo fato de que muitas pessoas passam anos estudando em escolas e todo este tempo parece não ser suficiente para que sejam boas leitoras, pois não logram ir além da decifração da escrita, sendo a decodificação insuficiente para resolver problemas relacionados à compreensão de textos.

A compreensão plena de um texto é fator relevante para uma leitura eficiente, já que compreender de fato o que se lê é necessário, pois se sabe que a leitura está presente no dia a dia das pessoas e, muito mais, nas atividades de trabalho de profissionais que utilizam o tempo todo a língua escrita, em língua materna e, também, em língua estrangeira. É, portanto, por meio da leitura que o ser humano adentra em novos campos de conhecimento que se perpetuam em livros ou documentos. A leitura proporciona a aquisição de novas informações, o aprendizado constante e, também, a inserção de forma mais completa na comunidade do conhecimento. Saber ler trata-se de uma necessidade fundamental para que uma pessoa possa atuar de forma ampla em sociedade, pois a leitura é também uma prática social e cultural (SOUZA, 2012; FLÔRES, 2008).

A proposta deste artigo é fazer uma revisão de literatura sobre o processo de leitura e da compreensão leitora, com destaque ao ensino da compreensão de textos expositivos, a fim de contribuir com a reflexão e a prática de professores no ensino de línguas. Nossa discussão terá como enfoque o texto expositivo, haja vista que, em muitos casos, os alunos demonstram maiores dificuldades de compreender esse tipo textual (BARETTA, 2008; BRAGA; SILVESTRE, 2002). Diferentemente dos textos narrativos, que fazem parte de nossa vida desde a nossa tenra infância por meio da contação de histórias, os textos expositivos entram em nossa vida muito mais tarde, na maioria das vezes apenas na escola, abordando conteúdos que em muitos casos nos são menos familiares, como por exemplo, assuntos científicos relacionados à saúde, a problemas econômicos, socioculturais, dentre outros (WILLIAMS, 2005; GRAESSER; GOLDING; LONG, 1991). Iniciamos nosso texto com a discussão sobre o processo de leitura, que requer a interação entre leitor, texto e contexto para que ela seja efetivada. A seguir, apresentamos os diferentes tipos de processos e fatores que envolvem essa imbricada e complexa tarefa que é a de dar sentido aos sinais gráficos dispostos na página (ou tela) à nossa frente, para, então, discutirmos o ensino da compreensão de textos expositivos e a importância fundamental do professor nesse processo, sugerindo o uso do reconto oral como uma alternativa para avaliação da compreensão leitora.

\section{0 processo de leitura}

É ponto pacífico na literatura a concepção de que dominar a leitura trata-se de uma demanda essencial do ser humano para que este ocupe um papel abrangente, tanto social quanto culturalmente. Principalmente em tempos de globalização e Internet em que as informações chegam de forma praticamente instantânea: a todo o momento, novas informações são publicadas e precisam ser interpretadas ao serem lidas, ouvidas ou assistidas. Essa multissemiose dos textos (ROJO, 2012) precisa ser lida de forma plena, para que se esteja inteirado do que ocorre nas diversas esferas do letramento das quais fazemos parte: trabalho, escola, lazer, dentre outras. Certamente, o domínio da compreensão em textos lidos será importante aliado da compreensão de recursos audiovisuais (KINTSCH; RAWSON, 2013; BARETTA; TOMITCH; MAcNAIR; LIM; 
WALDIE, 2009; FLÔRES, 2008; SOUZA, 2012; LIMA，2009; NEVES, 2003; COLOMER; CAMPS, 2002).

Quando se realiza uma leitura, normalmente, há uma finalidade, ou seja, há objetivo(s) ou intenção(ões) de acordo com a situação, o que é um fator determinante para a compreensão de um texto. A leitura é, portanto, um processo de interação entre leitor, texto e contexto, que precisam relacionar-se para que a compreensão se efetive. $\mathrm{Na}$ sociedade moderna lê-se em praticamente todas as atividades, já que a leitura perpassa diversos contextos e necessidades culturais e sociais dos indivíduos, tais como pegar um ônibus, realizar uma operação bancária no caixa eletrônico, enviar um e-mail, utilizar o celular para ler e enviar mensagens, ler um manual de instruções, ler sobre o tema da próxima aula, entre outros (BRAGA; SILVESTRE, 2002; SOLÉ, 1998; SMITH, 1989; KLEIMAN, 1989).

Dentre os fatores envolvidos no ato de ler, a memória possui um papel ímpar, principalmente a chamada memória de trabalho, fundamental no encadeamento da compreensão e que é ativada durante todo o processo de leitura (KINTSCH; RAWSON, 2013; BARETTA, 2008; FINGER-KRATOCHVIL, 2010). A memória de trabalho é importante para o ato de ler pois é o sistema de memória que, para além da função de armazenar, é também responsável por orquestrar as informações que entram por meio da nossa retina e são decifradas pelo nosso cérebro, juntamente com aquelas informações ativadas da memória de longo-prazo (BADDELEY, 2011). Assim, a construção do sentido daquilo que decodificamos se deve em razão do processamento dos traços presentes na página (ou tela) com a integração do conhecimento fonológico, lexical e semântico que já possuímos, que será, por sua vez, integrada ao conhecimento de mundo, armazenado na nossa memória de longo prazo.

Portanto, sabe-se no processo de ensino que o sistema de memória dos alunos leitores não está vazio. Ao iniciar a vida escolar, eles já trazem em sua bagagem conhecimento prévio diversificado sobre o mundo e sobre sua língua materna, conhecimentos esses advindos de sua vivência cotidiana; mas é na escola que se aprende formalmente a ler ${ }^{2}$, interpretar e compreender textos. É preciso, portanto, que os professores estimulem o ato de ler a todo o momento, por meio de práticas concretas de leitura, i.e., que sejam significativas para o aluno em diversas situações e contextos (SOUZA, 2012; SÁTIRO; PÜIG, 2000; KLEIMAN, 1989; SMITH, 1989). Dessa forma, é importante saber que a leitura sempre envolve produção de sentidos, compreensão de usos e valores sociais da escrita e também o gosto pela leitura. Ao ensinar leitura é preciso ter clareza a respeito da maturidade do indivíduo, para então fazer um planejamento pedagógico adequado que atenda às lacunas de aprendizagem verificadas pelo professor por meio de atividades que as diagnostiquem.

Ler é algo que se aprende, e esse aprendizado se faz praticando a leitura em diversos tipos textuais - narrativo, descritivo, dissertativo (expositivo e argumentativo), explicativo (injuntivo e prescritivo) -, em diversos gêneros ${ }^{3}$ (receita, cartaz, mensagem de texto, notícia, panfleto, infográfico, dentre muitos outros), contextos e objetivos, bem

\footnotetext{
${ }^{2}$ Temos consciência de que alguns alunos chegam à escola alfabetizados, i.e., são capazes de decodificar. Ao nos referirmos à aprendizagem da leitura não nos limitamos aos processos mais básicos, porém fundamentais que envolvem essa habilidade, mas igualmente aos processos de nível superior, conforme discutido na seção "A compreensão leitora" deste artigo.

${ }^{3} \mathrm{O}$ objetivo de nosso texto não é discutir a distinção entre tipo e gênero textual, nem primar um em detrimento do outro, mas propor a reflexão sobre o ensino do texto expositivo tendo como base sua estrutura retórica que se diferencia dos outros tipos textuais.
} 
como com o uso de estratégias que facilitem ou auxiliem na remediação de dificuldades, caso existam, tais como: a observação de gravuras, da fonte e da data de publicação, do uso de negrito, itálico e da repetição de palavras; o reconhecimento da organização textual e da ideia central; a releitura; dentre outros (SOUZA, 2012; SOUZA et al, 2010; BRAGA; SILVESTRE, 2002; COSTA et al, 2002; SOLÉ, 1998; FULGÊNCIO; LIBERATO, 1998).

A leitura é considerada um processo interativo, pois o sentido que um texto faz para um leitor passa a existir a partir do momento em que ocorre o contato entre texto, leitor e contexto (SOUZA, 2012; SÁTIRO; PÜIG, 2000; KLEIMAN, 1989; SMITH, 1989). O sentido que um texto fará para um leitor irá depender de inúmeros fatores intervenientes, como por exemplo:

contexto social, espaço e tempo de leitura, desejos e intenções do leitor, conhecimento prévio relevante compartilhado entre leitor e expressão textual do autor, estado físico e emocional do leitor, competência em leitura e situação em que a leitura acontece e/ou é requerida (SOUZA, 2012, p. 67).

Com relação ao processo de ensino/aprendizagem e alcance de compreensão leitora, percebe-se que grande parte da atenção está voltada, portanto, à própria aprendizagem da leitura - e torna-se importante ressaltar, novamente, que se aprende a ler lendo, por meio das práticas constantes de leitura (GUIMARÃES; RIBAS, 2015; BARETTA; FINGER-KRATOCHVIL; SILVEIRA, 2012). "A aprendizagem da leitura e da escrita requer ensino" (BRESSON, 2001, p. 25), pois para que a leitura seja corretamente ensinada e o aprendizado de fato ocorra, este precisa ser significativo, pois "somos capazes de lembrar muito melhor aqueles detalhes de um texto que tem a ver com um objetivo específico" (KLEIMAN, 1989, p. 30-31). Assim, quando se tem um propósito real, que faz parte de um contexto social interativo, a leitura faz mais sentido àquele que lê.

Neste processo de ensino e aprendizagem da leitura, apesar de não ser o único responsável, o docente possui um papel fundamental (GUIMARÃES; RIBAS, 2015; BARETTA; FINGER-KRATOCHVIL; SILVEIRA, 2012; SMITH, 1989) na formação do leitor. Assim, o professor deve buscar fazer com que a leitura desperte discussões sobre o tema lido, além de instigar os alunos a buscar respostas e soluções que os tirem da acomodação e os tornem pessoas mais críticas. Quando os alunos não entendem a relevância de uma determinada atividade de leitura, é tarefa do professor lhes mostrar que vale a pena, assim como apresentar-lhes objetivos e estratégias, i.e., ações conscientes, adotadas pelo leitor para transformar automatismos (habilidades) como velocidade, precisão, complexidade, em "estratégias" que auxiliarão na compreensão (PARIS, LIPSON; WIXSON, 1983; BARETTA, 1998; KOPKE FILHO, 2002), necessárias para elucidar a atividade, tornando-a significativa. Se os alunos possuírem dificuldades para ler, o docente deve, inicialmente, diagnosticar quais as possíveis razões para tais dificuldades e, então, providenciar o auxílio na efetivação da leitura (MARIA, 2002; SOLÉ, 1998).

Alcançar a leitura proficiente requer do leitor conhecer seus objetivos de leitura e saber quais estratégias são necessárias para que a compreensão se efetive. Além de saber quais estratégias, o leitor proficiente é aquele que sabe "quando" e "como" utilizar essas estratégias (PARIS, LIPSON; WIXSON, 1983), de modo que a informação trazida pelo texto seja construída juntamente com o apoio do conhecimento prévio inerente ao leitor (KINTSCH; RAWSON, 2013; SOUZA et al, 2010; FLÔRES, 2008; CAFIERO, 2005; NEVES, 2003; FULGÊNCIO; LIBERATO, 1998). Por essa razão, é fundamental que o professor promova atividades de leitura as quais estimulem seus 
alunos a se tornarem leitores proficientes nos diversos contextos de interação com o texto.

Discutimos neste texto o trabalho com a leitura de textos expositivos, pois estes costumam apresentar informações e fatos que fomentam o pensamento analítico dos estudantes, preparando-os melhor para atuar de forma participativa e crítica na sociedade e, a partir desse conhecimento, tomar decisões e compreender de maneira aprofundada situações sociais, políticas, culturais, dentre outras (FERRAREZI JR.; CARVALHO, 2017; SOUZA, 2012; LIMA, 2009; WILLIAMS, 2005). Na próxima seção, será abordado o complexo processo de compreensão leitora.

\section{Compreensão leitora}

A compreensão leitora envolve diferentes processos, que, de acordo com Gagné, Yekovich e Yekovich (1993), subdividem-se em dois grupos: aqueles inerentes ao conhecimento declarativo e aqueles inerentes ao conhecimento procedimental. No primeiro grupo, estão os processos mais básicos, porém fundamentais para que a leitura se efetive: o conhecimento de letras, fonemas, morfemas, palavras, ideias e tópicos que proverão ao leitor o conhecimento necessário para que a escrita seja compreendida. Dominados esses conhecimentos, os leitores passam para o conhecimento procedimental, que envolve o conhecimento sobre habilidades e estratégias. Conforme proposto por Gagné e colaboradores, os leitores precisam, primeiramente, ser capazes de decodificar, processo este que se subdivide em associação e recodificação. Neste nível, os leitores decodificam as palavras, associam o que leram com seu léxico mental e, se não há pareamento entre os dois, eles as recodificam. No próximo nível, os leitores focam sua atenção na compreensão literal, momento em que se atêm ao léxico e analisam as frases do texto em busca do significado. O próximo nível, o da geração de inferências, é alcançado por meio dos processos de integração, sumarização e elaboração das informações apresentadas no texto que permitem que o leitor vá além da informação literal. No nível do monitoramento da compreensão, o leitor busca constantemente avaliar sua compreensão e, para tanto, estabelece um objetivo para sua leitura para, então, selecionar as estratégias necessárias para alcançá-lo e verificar se o objetivo foi alcançado; caso não seja, o leitor buscará uma ou mais estratégias para remediar o problema ${ }^{4}$. A compreensão textual, portanto, é a última fase da (aprendizagem de) leitura e depende de todos os processos que a envolvem na relação texto-leitor-contexto para acontecer de fato (KINTSCH; RAWSON, 2013; SÁNCHEZ MIGUEL; PÉREZ; PARDO, 2012; McGUINNESS, 2006; COLOMER; CAMPS, 2002; SOLÉ, 1998).

Ademais, segundo Kleiman (1989, p. 13), a compreensão textual é caracterizada "pela utilização de conhecimento prévio: o leitor utiliza na leitura o que ele já sabe, o conhecimento adquirido ao longo de sua vida". Conforme a autora, a interação dos vários níveis de conhecimento prévio, tais como o linguístico, o textual e o conhecimento de mundo (enciclopédico), é o que permite que o leitor consiga construir o sentido de um texto. A leitura é considerada um processo interativo justamente porque o leitor faz uso desses inúmeros níveis de conhecimento e esses níveis interagem entre

\footnotetext{
${ }^{4}$ Para uma representação dos diferentes níveis e processos envolvidos na leitura, ver o gráfico apresentado em Andrade, Gil e Tomitch, 2012, p. 16, desenvolvido pela terceira autora, a partir de Gagné, Yekovich e Yekovich, 1993.
} 
si. Para a autora, sem o conhecimento prévio do leitor não é possível haver a devida compreensão. Para melhor esclarecimento a respeito do conhecimento prévio, tratar-seá de cada uma de suas variedades.

O conhecimento prévio linguístico é aquele que está implícito, não verbalizado, e passa pelo conhecimento da pronúncia de uma língua, pelo conhecimento vocabular, pelas regras da língua e pelo conhecimento a respeito do seu uso.

Há também o conhecimento textual, que está ligado ao conjunto de noções e conceitos a respeito dos elementos componentes do texto; é também conhecimento prévio e possui um importante papel no processo de compreensão de textos. É elementar que se conheça a estrutura de um determinado tipo ou gênero de texto, bem como suas peculiaridades para que se possa compreendê-lo eficazmente (SÁNCHEZ MIGUEL; PÉREZ; PARDO, 2012; FLÔRES, 2008; KLEIMAN, 1989).

Outro conhecimento prévio que também é determinante na compreensão textual é o conhecimento de mundo, também chamado de conhecimento enciclopédico. Este é de suma relevância no sucesso do decurso da interpretação e compreensão textual, porque quando uma pessoa desconhece uma temática ou alguma informação a respeito dessa temática, a compreensão fica prejudicada. Em muitas situações, um leitor não será capaz de realizar inferências, ou seja, estabelecer uma relação de raciocínio lógico, por não ter referência histórica, geográfica ou de qualquer outra área de conhecimento relativo àquilo que está lendo (KLEIMAN, 1989). No ensino de leitura, é muito importante que se considere este conhecimento, pois se sabe que nenhuma pessoa inicia uma leitura sem ter nenhum conhecimento em sua mente, pois "o ser humano constrói o que sabe sobre a realidade, desde o nascimento, não sendo o cérebro/mente um recipiente a ser preenchido unicamente pelo saber escolar" (FLÔRES, 2007, p. 55). É a participação cultural que faz com que um significado seja coletivo (público), já que o meio cultural no qual alguém está inserido constitui-se da soma de sentidos e de conceitos que são elaborados publicamente.

Como pudemos perceber, a compreensão textual depende de todos os conhecimentos prévios de um leitor e, segundo Kintsch e Rawson (2013), ela ocorre em vários níveis, tais como o nível linguístico, momento em que ocorre a decodificação de símbolos gráficos e reconhecimento de palavras, o nível semântico, no qual é realizada a significação do texto e a formação de ideias ou proposições, e o nível chamado de base textual, que está ligado ao significado do texto tal e qual está descrito nele. $\mathrm{O}$ domínio das informações do texto somado às inferências (acréscimo de informações a partir dos conhecimentos prévios) levam o leitor à compreensão profunda do texto, chamada de modelo de situação (KINTSCH; RAWSON, 2013; SÁNCHEZ MIGUEL; PÉREZ; PARDO, 2012; COLOMER; CAMPS, 2002).

Conforme percebemos nesta breve revisão de literatura, a compreensão de textos exige mais do que apenas decodificar, entender o vocabulário e a relação entre as ideias

dispostas no texto. É preciso que se saiba fazer o reconhecimento de palavras-chave, da principal temática do texto, da relação entre as informações (concorrentes ou não) dispostas nos parágrafos, bem como da estrutura textual. Além disso, o leitor precisa realizar conexões entre o conteúdo do texto com suas próprias experiências. A seguir, apresentar-se-ão dois fatores - de aprendizado e de texto - que podem influenciar significativamente neste processo.

\subsection{Fatores de aprendizado}


Conforme Kintsch e Kintsch (2005), a compreensão textual irá depender da capacidade do leitor de decodificar rápida e eficientemente o código escrito. Além desses fatores básicos, mas não menos importantes, deve-se levar em consideração, também, o conhecimento de mundo e a motivação como fatores relevantes para que ocorra o sucesso da compreensão.

Além disso, a compreensão de textos é formada por conhecimentos metacognitivos e metalinguísticos. O conhecimento metacognitivo, i.e., a compreensão e seleção efetiva de uso de estratégias durante a leitura, permite que os alunos adquiram mais conhecimento a respeito de um texto, já que leitores proficientes dominam diversas estratégias de leitura e, também, monitoram sua compreensão enquanto estão lendo - por exemplo, se não entendem algum trecho, releem ou buscam palavras desconhecidas no dicionário. As estratégias metacognitivas são, portanto, aquelas que estão ligadas ao planejamento (definição dos objetivos) e monitoramento da leitura (o leitor percebe como está sua compreensão e se não estiver compreendendo bem, sabe como fazer uso de estratégias para melhor compreender) (PARIS, LIPSON; WIXSON, 1983; GAGNÉ; YEKOVICH; YEKOVICH, 1993; PINTRICH, 2002; CULATTA; HORN; MERRITT, 1998; CROPLEY, 1996).

Já o conhecimento metalinguístico está relacionado à capacidade de compreender e falar sobre linguagem. Em nível textual, as habilidades metalinguísticas podem abarcar a competência de identificar a estrutura do texto, bem como de usar essa capacidade para melhor compreender, o que é muito importante, já que entender características estruturais de determinado tipo ou gênero textual é parte integrante do processo de compreensão (CULATTA; HORN; MERRITT, 1998; WESTBY, 1994).

Duke e Pearson (2002) e Pressley e Afflerback (1995) afirmam que os fatores de aprendizado são dominados pelos leitores proficientes, que são aqueles que conseguem fazer uso de várias estratégias; que reconhecem a estrutura do texto; que observam questões que possam ser importantes de acordo com seus objetivos de leitura; que monitoram sua compreensão textual, e, se necessário, realizam ajustes durante a leitura; que revisam e fazem resumos mentais do que leram para melhor compreender.

\subsection{Fatores de texto}

O texto em si possui papel fundamental no processo de compreensão. Os textos apresentam importantes características que atuam no desempenho dos leitores. Uma delas está ligada ao nível de organização global do texto, que se refere a um nível mais amplo de conexão das ideias principais do texto, ou seja, a macroestrutura textual, como por exemplo: relações de comparação, contraste, classificação, descrição, dentre outros. Outra tem relação com o nível local do texto, ou seja, com as inter-relações entre as sentenças de um texto, a coesão textual (costura das ideias apresentadas no texto). Neste nível, considera-se no texto a forma como cada nova ideia se relaciona com a anterior por meio de laços coesivos locais (sinônimos, conjunções, pronomes, conectivos e outros), que organizam o texto usando meios gramaticais e semânticos a fim de alcançar conexão no nível local.

Ambas as características textuais são importantes e colaboram para o sucesso da compreensão textual e, por essa razão, precisam ser dominadas concomitantemente e relacionadas com os fatores de aprendizado (BURTON, 2008; CULATTA et al., 1998; 
LORCH; LORCH; INMAN, 1993; CARLISLE, 1991; MEYER; RICE， 1984; KINTSCH; YARBROUGH, 1982; HALLIDAY, 1975).

Percebe-se até aqui quão complexo é o processo de compreensão leitora, e é possível notar a importância de se ensinar estratégias de leitura para que os alunos possam compreender melhor o que leem. Expostos os conceitos fundamentais que envolvem o processo de compreensão, trataremos, na segunda metade deste texto, sobre o ensino da compreensão leitora de textos expositivos.

\subsection{O ensino da compreensão de textos expositivos}

No ensino de compreensão de textos expositivos é preciso levar em consideração o fato de que os alunos estão mais habituados com os textos narrativos do que com os expositivos, conforme mencionado no início deste artigo. Segundo Graesser, Golding e Long (1991), os textos narrativos, em geral, apresentam personagens e se assemelham a situações e experiências do cotidiano, pois apresentam diálogos e ações do dia a dia, como por exemplo, uma conversa entre amigos, uma viagem, a leitura de um conto, entre outros.

Weaver e Kintsch (1991) afirmam que, ao contrário das narrativas, os textos expositivos possuem a principal função de comunicar e informar, como por exemplo, textos que apresentam informações técnicas, acadêmicas, relativas ao ambiente profissional, entre outras. Por essa razão, possuem conteúdos que são, de forma geral, menos familiares para os estudantes do que os assuntos apresentados pelos textos narrativos.

Os textos expositivos normalmente são escritos com vocabulário e conceitos menos conhecidos do público estudantil que os narrativos, como no caso de artigos científicos. A narrativa faz parte do dia a dia das pessoas: usa-se a narração para contar o que ocorreu em um dia de estudo ou trabalho, em um supermercado, na rua, dentre outras situações comuns do cotidiano (WILLIAMS, 2005; WEAVER; KINTSCH, 1991; MEYER; RICE, 1984), ao passo que o texto expositivo é usado para, por exemplo, informar sobre a situação política do país ou descrever os últimos avanços acerca das pesquisas contra o câncer.

Portanto, com relação ao ensino da compreensão de textos expositivos, é importante saber que, se os alunos não tiverem uma boa noção das suas características textuais, bem como o domínio de estratégias de compreensão relevantes, eles possivelmente terão dificuldades quando se depararem com esse tipo textual e seus respectivos gêneros durante as aulas e em seu dia a dia (BURTON, 2008; DICKSON et al, 1998; KINDER; BURSUCK, 1991).

Segundo Duke (2000), Duke e Pearson (2002) e Dymock (2005), apesar de alguns professores estarem familiarizados com a estrutura do texto expositivo, nem sempre conseguem utilizar estratégias de compreensão desse tipo textual em suas práticas de ensino, e o ensino dessas estratégias é fundamental para que os alunos consigam compreender plenamente esses textos. Logo, é importante que os professores monitorem de forma contínua a compreensão de seus alunos - se estão sabendo usar as estratégias adequadas, se estão compreendendo o que leram -, bem como ensiná-los a ler e compreender textos. Caso o professor, ao fazer a avaliação da compreensão leitora por meio de atividades orais de discussão ou de teste de verificação escrito, perceba que alguns alunos estão com dificuldades, deve realizar atividades extras com abordagens 
diferentes das já utilizadas regularmente em sala. O professor deve sempre monitorar como está a compreensão dos seus alunos, pois essa ação o auxilia na escolha de práticas de intervenção que deve implementar ou enfatizar para aprimorar cada vez mais o processo de compreensão leitora de seus estudantes. Percebe-se, portanto, o quão fundamental é o papel do professor nesse processo de ensino e é sobre isso que o próximo tópico irá tratar.

\section{A importância do papel do professor no processo de ensino da compreensão leitora de textos expositivos}

Conforme visto, a compreensão é uma tarefa complexa que depende dos conhecimentos e habilidades do aluno e dos fatores de texto e aprendizado. As demandas dos textos expositivos aumentam ao longo da escola, como no caso de estudantes de ensino médio, que passam a ler mais artigos científicos, por exemplo. Por isso, os estudantes devem desenvolver habilidades e estratégias para processá-los de forma eficiente. Deve haver uma correspondência entre aquilo que os alunos sabem sobre os textos e aquilo que o tipo de texto exige que eles compreendam (BURTON, 2008).

Assim sendo, o professor precisa estar atento a alguns fatores que podem interferir na compreensão de textos expositivos na escola, como a compreensão de forma clara das características desse tipo textual e o domínio das estratégias de compreensão. É preciso, ainda, conforme já mencionado, saber que os alunos devem se familiarizar com a estrutura do texto expositivo. Por essa razão, o papel do professor é fundamental e este deve saber escolher (bem) quais textos serão usados no ensino da compreensão, usando não apenas os textos do livro didático, mas outros textos autênticos a fim de que os alunos tenham contato com o maior número de textos possível, sejam eles bem estruturados ou não, haja vista que o aluno nem sempre terá contato apenas com textos bem escritos. Os docentes também precisam dominar as características estruturais do texto expositivo e ensiná-las juntamente com o ensino das estratégias de compreensão, pois os alunos dificilmente desenvolvem uma variedade de estratégias de maneira autônoma, sem instrução direta do professor (BURTON, 2008; DYMOCK, 2005; DUKE, 2000; SOLÉ, 1998; BARETTA, 1998).

Além disso, os professores precisam utilizar mecanismos para monitorar o progresso de compreensão de seus alunos e realizar o acompanhamento do desempenho daqueles que demonstram dificuldades para empregar as estratégias de compreensão. Com o objetivo de auxiliar os professores de ensino de línguas a identificar os leitores que demonstram fragilidades no processo de compreensão, avaliar a efetividade do ensino e monitorar o avanço individual de cada aluno, propomos o uso do reconto oral como atividade de medição e ensino da compreensão de textos expositivos.

Tradicionalmente, o reconto, que também é uma forma de narração, é utilizado para que alunos desenvolvam sua compreensão textual ao recontarem, por escrito, textos narrativos, permitindo que professores avaliem a sua compreensão. Além disso, de acordo com Moss e Loh (2012), o reconto proporciona aos professores a possibilidade de verificar a quantidade de informações que seus alunos retêm (i.e., compreenderam) depois de ler ou escutar um texto. De acordo com os autores, o reconto reflete o que os alunos entenderam dos textos e fornece informações a respeito das habilidades leitoras (ou as dificuldades) desses estudantes. Moss (2004), Gambrell, 
Pfeiffer e Wilson (1985) e Johnston (1997) afirmam que os recontos são uma das melhores e mais eficientes estratégias de avaliação para descobrir se um aluno realmente compreendeu o que leu. Moss e Loh (2012) afirmam que atividades de reconto, tanto escritas como orais, fazem com que os alunos possuam um papel efetivo no processo de reconstrução de um texto, o que lhes demandará precisão no ato de ler e compreender o que leram.

Segundo Burton (2008), as atividades de reconto fornecem informações sobre a capacidade dos estudantes de recuperar detalhes, fazer inferências e reconhecimentos de relacionamentos estruturais. Essas estratégias normalmente não são avaliadas em baterias de diagnóstico ou inventários de leitura informal, que tradicionalmente são utilizadas como avaliações de compreensão. Uma importante vantagem do reconto, de acordo com o pesquisador, é que ele pode ser trabalhado em sala de aula de forma escrita ou oral. O reconto escrito pode parecer mais fácil de avaliar, pois o professor tem uma "prova" física para refletir a respeito do processo de compreensão, mas pode ser menos reflexivo em relação à compreensão dos alunos, pois na escrita as demandas complicam linguística e formalmente a tarefa de reportar o que foi lido, podendo, dessa forma, ocultar o processo de compreensão. Além disso, como o leitor terá mais tempo para refletir e realizar mudanças em seu relato, é possível que esses fatores também acabem por mascarar a compreensão real do que foi lido.

Burton afirma que o reconto oral é uma ferramenta bastante efetiva para a avaliação da compreensão de textos expositivos, porque fornece mais informações sobre a capacidade de compreensão de um aluno do que atividades tradicionais de compreensão, tais como perguntas abertas e semiabertas, de múltipla escolha, de completar, relacionar colunas, dentre outras. As atividades de reconto oral são também bastante valorizadas por Sudweeks, Glissmeyer, Morrison, Wilcox e Tanner (2004), os quais relatam que, para aumentar a probabilidade de haver a medição da compreensão individual da organização de um texto que seja realmente baseada no desempenho do aluno, devem ser utilizadas avaliações que incluam relatos orais.

Diante disso, é possível inferir que, com o uso do reconto oral como forma de monitoramento da aprendizagem de compreensão textual, o professor reunirá informações que o permitirão verificar o nível de compreensão dos seus alunos após lerem textos expositivos, pois o texto recontado demonstrará detalhes da compreensão individual e, conforme argumentado por diferentes pesquisadores (BURTON, 2008; MOSS e LOH, 2012; SUDWEEKS e colaboradores, 2004), o reconto oral torna-se mais eficaz que o escrito. De acordo com as observações e reflexões desses pesquisadores, no reconto oral o aluno-leitor não tem tempo para fazer reflexões e corrigir seu relato, sendo, portanto, mais eficiente para o professor-pesquisador realizar avaliação das reais capacidades leitoras que os alunos possuem.

O reconto oral pode ser trabalhado em sala de aula tanto de ensino fundamental quanto de ensino médio, já que se trata de uma importante ferramenta de avaliação de compreensão textual, mas é importante que o texto esteja adequado à faixa etária dos alunos. O professor pode utilizar o reconto oral de forma dinâmica, deixando um momento da aula reservado para que determinado número de alunos realize o reconto de um texto previamente lido por toda a turma. Pode, ainda, aproveitar a simpatia que os alunos têm pelas tecnologias e, após eleger um texto, solicitar que eles, individualmente ou em grupos, façam, em momento extraclasse, a filmagem com o próprio celular recontando o texto que leram. Sugere-se que a apresentação seja feita em sala, para que toda a turma analise e discuta a respeito da compreensão do texto, bem como o 
professor aproveite a análise para apresentar as estratégias de compreensão, ensinandoas aos alunos, para que estes aprendam a usá-las de maneira autônoma, tornando-se, assim, leitores proficientes. Para respaldar professores que tenham interesse em utilizar o reconto oral em suas aulas, apresentamos, a seguir, o quadro de avaliação da compreensão leitora por meio do reconto oral, traduzido e adaptado de Burton (2008).

\begin{tabular}{|c|c|}
\hline Pontuação & Observações \\
\hline 4 Exemplar & $\begin{array}{l}\text { - Reconta com precisão conceitos importantes extraídos do texto com suas próprias } \\
\text { palavras; } \\
\text { - Inclui detalhes chaves do texto; } \\
\text { - Utiliza estrutura apropriada do texto expositivo através do reconto, como por } \\
\text { exemplo, a ordem sequencial, relações de causa/efeito, comparação e contraste, entre } \\
\text { outros. }\end{array}$ \\
\hline 3 Proficiente & $\begin{array}{l}\text { - Explica conceitos importantes do texto com suas próprias palavras; } \\
\text { - Inclui a maioria dos detalhes principais do texto; } \\
\text { - Usa estrutura apropriada do texto expositivo através do reconto, como por exemplo, } \\
\text { a ordem sequencial, relações de causa/efeito, comparação e contraste, entre outros; } \\
\text { - Utiliza algumas palavras-chave do texto. }\end{array}$ \\
\hline 2 Básico & $\begin{array}{l}\text { - Demonstra compreensão parcial dos conceitos principais do texto, entretanto repete } \\
\text { as palavras do autor; } \\
\text { - Compreende alguns detalhes do texto, porém de forma aleatória; } \\
\text { - A estrutura do reconto não é clara; } \\
\text { - Inclui pouco vocabulário contido no texto. }\end{array}$ \\
\hline 1 Limitado & $\begin{array}{l}\text { - Utiliza informações limitadas no momento do reconto; } \\
\text { - Transmite pouco ou nenhum entendimento sobre o texto lido; } \\
\text { - Pode incluir informações imprecisas, confusas ou omitir dados expostos no texto; } \\
\text { - Informações sem relação com o tema abordado no texto. }\end{array}$ \\
\hline
\end{tabular}

Fonte: BURTON, R. C. Oral Retelling as a Measure of Reading Comprehension: The Generalizability of Ratings of Elementary School Students Reading Expository Texts. 2008. Disponível em: <https://scholarsarchive.byu.edu/etd/1678/>. Acesso em: 10 mai. 2018.

\section{Considerações finais}

Com base no sucinto arcabouço teórico apresentado no presente artigo, entendese que é muito importante que textos expositivos sejam trabalhados ativamente nas aulas de línguas, já que este tipo textual possui uma relevante função que engloba comunicação, informações, fatos, dentre outros, que instigam a postura crítica de quem lê - e é por meio do contato com esses textos que os alunos conseguirão obter uma melhor compreensão dessa tipologia textual. É fundamental que os professores conheçam bem as estratégias de leitura e saibam como usá-las em suas práticas, para que, dessa forma, estejam aptos a ensiná-las a seus alunos.

Vale destacar o quão interessante é que se trabalhe com recontos orais em sala a fim de monitorar e avaliar como está o nível de compreensão leitora dos alunos, para que se saiba quais são as estratégias a serem ensinadas e se houve avanços de compreensão no decorrer dos recontos realizados. Assim, os professores de línguas 
podem ir além dos textos narrativos, já conhecidos pelos alunos, e levá-los a compreender as características dos textos expositivos para, dessa maneira, construir posturas críticas diante de textos e contextos em geral. Agindo dessa forma, os docentes podem fazer com que esses alunos se tornem proficientes e preparados para atuar em sociedade, já que a leitura é um processo social e cultural presente no dia a dia das pessoas e é de suma importância possuir as habilidades para uma compreensão textual profunda para ser um cidadão crítico.

\section{REFERÊNCIAS}

ANDRADE, A.M. T. de; GIL, G.; TOMITCH, L. M. B. Percepção de Estratégias de Leitura em LE de alunos universitários. (Con)Textos Linguísticos. Vitória, v. 6, n. 6, p. 7 - 17, 2012.

BADDELEY, A. Memória de Trabalho. IN: BADDELEY, A.; ANDERSON, M. C.; EYSENCK, M.W. Memória. Porto Alegre: ARTMED, 2011, p. 54-82.

BARETTA, L. The performance of proficient EFL readers when reading to recall and to summarize expository texts. 1998. Dissertação (Mestrado em Letras Inglês).

Universidade Federal de Santa Catarina, Florianópolis. Disponível em: https://repositorio.ufsc.br/bitstream/handle/123456789/77366/149254.pdf?sequence=1. Acesso em: 11 ago. 2017.

The Process of Inference Making in Reading Comprehension: An ERP

Analysis. 2008. Tese (Doutorado em Letras Inglês). Universidade Federal de Santa Catarina, Florianópolis. Disponível em:

https://repositorio.ufsc.br/handle/123456789/91884 Acesso em: 11 ago. 2017.

TOMITCH, L.M.B., McNAIR, N., LIM, V.K.; WALDIE, K.E. (2009) Inference making while reading narrative and expository texts: An ERP study. Psychology \& Neuroscience, 2, 2, p. 137-145.

; FINGER-KRATOCHVIL, C.; SILVEIRA, R. A percepção do leitor-professor em formação e seu desempenho em leitura. In: VENTURINI, M. C.; BIAZI, T. M. D.; OLIVEIRA, S. E. de. (Org.). O professor no Brasil: dizeres contemporâneos. 1 ed. Guarapuava: Editora da UNICENTRO, 2012, v. 01, p. 143-178.

BRAGA, R. M.; SILVESTRE, M. F. Construindo o leitor competente: Atividades de leitura interativa para a sala de aula. São Paulo: Petrópolis, 2002.

BRESSON, F. A leitura e suas dificuldades. In: CHARTIER, R. (org.) et al. Práticas da Leitura. Tradução: Cristiane Nascimento. São Paulo: Estação Liberdade, 2001.

BURTON, R. C. Oral Retelling as a Measure of Reading Comprehension: The

Generalizability of Ratings of Elementary School Students Reading Expository Texts.

2008. All Theses and Dissertations. Disponível em:

<https://scholarsarchive.byu.edu/etd/1678/>. Acesso em: 10 mai. 2018.

CAFIERO, D. Leitura como processo: caderno do professor. Belo Horizonte:

Ceale/FaE/UFMG, 2005.

CARLISLE, J. F. Language comprehension and text structure. In: KAVANAGH, J. F. (org.). The language continuum from infancy to literacy. Parkton, MD: York Press, p. 115-145, 1991.

COLOMER, T.; CAMPS, A. Ensinar a ler, ensinar a compreender. Trad. Fátima

Murad. Porto Alegre: Artmed, 2002. 
COSTA, M. J. D. et al (orgs.). Línguas: ensino e ações. Florianópolis: UFSC/NUSPPLE, 2002.

CROPLEY, A. J. Fostering the growth of high ability. Norwood, NJ: Ablex, 1996.

CULATTA, B., HORN, D. G.; MERRITT, D. D. Expository text: Facilitating comprehension. In: MERRITT, D. D.; CULATTA, B. (orgs.) Language intervention In: the classroom. San Diego: Singular, p. 215-275, 1998.

DEHAENE, S. Os neurônios da leitura: como a ciência explica a nossa capacidade de ler. Porto Alegre: Penso, 2012.

DICKSON, S. V.; SIMMON, D. C.; KAMEENUI, E. J. (1998). Text organization and its relation to reading comprehension: A synthesis of the research. Technical Report

Special Educations Progrm. Washington D.C. Retrieved April 6, 2007, from ERIC database.

DUKE, N. K. 3.6 minutes per day: The scarcity of informational texts In: the first grade. Reading Research Quarterly, 35, p. 202-224, 2000.

; PEARSON, P. D. In: FARSTRUP, A; SAMUELS, S. (orgs.). What Research Has to Say About Reading Instruction. International Reading Association. Newark, p. 205-242, 2002.

DYMOCK, S. Teaching expository text awareness. The Reading Teacher, 59(2), p. 177$182,2005$.

FERRAREZI JR, C.; CARVALHO, R. S. de. De alunos a leitores: o ensino da leitura na educação básica. São Paulo: Parábola Editorial, 2017.

FINGER-KRATOCHVIL, C. Estratégias para o desenvolvimento da competência lexical: relações com a compreensão em leitura. 2010. Tese (Doutorado em Letras) Universidade Federal de Santa Catarina, Florianópolis. Disponível em:

<https://repositorio.ufsc.br/handle/123456789/94372 > Acesso em 31 jan. 2017.

FLÔRES, O. C. Como avaliar a compreensão leitora. Signo. Santa Cruz do Sul, v. 32, n. 53, p. 54-65, dez. 2007.

(org.). Linhas e entrelinhas: leitura na sala de aula. Santa Cruz do Sul:

EDUNISC, 2008.

FULGÊNCIO, L.; LIBERATO, Y. G. Como facilitar a leitura. 3. ed. São Paulo:

Contexto, 1998.

GAGNÉ, E. D.; YEKOVICH, C. W.; YEKOVICH, F. R. Reading. In: GAGNÉ, E. D.; YEKOVICH, C. W.; YEKOVICH, F. R. The cognitive psychology of school learning. New York: Harper Collins College Publishers, 1993, p. 267-312.

GAMBRELL, L. B.; PFEIFFER, W.; WILSON, R. The effects of retelling upon Reading comprehension and recall of text information. Journal of Educational Research, 78, p. 216-220, 1985.

GRAESSER A., GOLDING, J. M., \& LONG, D. L. Narrative representation and comprehension. In: BARR, R; KAMIL, M. L.; MOSENTHAL, P.; PEARSON, P. D. (orgs) Handbook of reading research. White Plains, NY: Longman, vol. 2, p. 171-205, 1991.

GUIMARÃES, G.; RIBAS, M. C. Literatura na universidade: dos conceitos pedagógicos à fruição literária. In: WILSON, V.; MORAIS, J. F. S. (orgs.). Leitura, escrita e ensino: discutindo a formação de leitores. São Paulo: Summus, 2015.

HALLIDAY, M. A. K. Learning how to mean: Exploration in the development of language. London, England: Edward Arnold, 1975.

JOHNSTON, P. H. Knowing literacy: Constructive literacy assessment. Portland, ME:

Stenhouse, 1997. 
KINDER, D.; BURSUCK, W. The search for a unified social studies curriculum: Does history really repeat itself? Journal of Learning Disabilities, 24(5), p. 270-275, 1991.

KINTSCH, W.; YARBROUGH, J. C. Role of rhetorical structure in text comprehension. Journal of Educational Psychology, 74, 828-834, 1982.

; KINTSCH, E. Comprehension. In: PARIS, S.; STAHL, S. (orgs.). Children's

Reading Comprehension and Assessment. Lawrence Erlbaum Associates. Mahwah, NJ, p. 71-92, 2005.

; RAWSON, K. A. Compreensão. In: A ciência da leitura. SNOWLING, M. J.; HULME, C. (orgs). Porto Alegre: Penso, 2013. p. 227-244.

KLEIMAN, A. Texto e leitor: aspectos cognitivos da leitura. Campinas: Pontes, 1989.

KOPKE FILHO, H. Repertório de estratégias de compreensão da leitura e

conhecimento metacognitivo de professores de língua portuguesa. Psicologia Escolar e Educacional, v. 06, n. 01, p. 67-80, 2002.

LIMA, D. C. de (org.). Ensino Aprendizagem de língua inglesa: conversas com especialistas. São Paulo: Parábola Editorial, 2009.

LORCH, R. F.; LORCH, E. P.; INMAN, W. E. Effects of signaling topic structure on text recall. Journal of Educational Psychology, 85(2), p. 281-290, 1993.

MARIA, L. de. Leitura e colheita: livros, leitura e formação e formação de leitores. Petrópolis: Vozes, 2002.

McGUINNESS, D. O ensino da leitura: o que a ciência nos diz sobre como ensinar a ler. Trad. Luzia Araújo. Porto Alegre: Artmed, 2006.

MEYER, B. J. F.; RICE, G. E. The structure of text. In: BARR, R.; KAMIL, M. L.; MOSENTHAL, P.; PEARSON, P. D. (orgs.) Handbook of Reading Research. New York: Longman, 1984.

MORAIS, J. Criar leitores: para professores e educadores. Barueri: Minha Editora, 2013.

MOSS, B. Teaching expository text structures through information trade book retellings. The Reading Teacher, 57, p. 710-718, 2004.

; LOH, V. S. 35 estratégias para desenvolver a leitura com textos informativos.

Trad. Marcelo de Abreu Almeida. Rev. Tec. Magali Lopes Endruweit. Porto Alegre: Penso, 2012.

NEVES, R. da C. O ensino de leitura em língua materna a partir do desenvolvimento de estratégias de leitura em língua estrangeira. SOLETRAS. São Gonçalo, v. 3, p. 160-175, 2003. Disponível em: <http://www.e-

publicacoes.uerj.br/index.php/soletras/article/viewFile/4467/3269> Acesso em: 28 nov. 2017.

PARIS, S.; LIPSON, M.; WIXSON, K. Becoming a strategic reader. Contemporary

Educational Psychology, 8(1), p. 293-316, 1983.

PINTRICH, P. The role of metacognitive knowledge In: learning, teaching, and assessing. Theory Into Practice, 41(4), p. 219-225, 2002.

PRESSLEY, M.; AFFLERBACH, P. Verbal protocols of reading: The nature of constructively responsive reading. Hillsdale, NJ: Erlbaum, 1995.

ROJO, R. Pedagogia dos multiletramentos: diversidade cultural e de linguagem na escola. In: ROJO, R.; MOURA, E. (orgs.). Multiletramentos na escola: São Paulo: Parábola Editorial, 2012, p. 11-31.

SÁNCHEZ MIGUEL, E.; PÉREZ, J. R. G.; PARDO, J. R. Leitura na sala de aula: como ajudar os professores a formar bons leitores. Porto Alegre: Penso, 2012. 
SÁTIRO, A.; PÜIG, I de. Brincar de pensar: livro de orientação para o professor. São Paulo: Callis, 2000.

SCLIAR-CABRAL, L. Neurociência: novo enfoque epistemológico. In: BUCHWEITZ, A.; MOTA, M. B. Linguagem e cognição: processamento, aquisição e cérebro. Porto Alegre: EDIPUCRS, 2015.

SMITH, F. Compreendendo a leitura: uma análise psicolinguística da leitura e do aprender a ler. Tradução: Daise Batista. Porto Alegre: Artes Médicas, 1989.

SOLÉ, I. Estratégias de Leitura. Porto Alegre: Penso, 1998.

SOUZA, A.C. Leitura emergente: a alfabetização como chave à produção de sentidos a partir do escrito. In: ; COSTA GARCIA, W.A. A produção de sentidos e o

leitor: os caminhos da memória. 1. ed. Florianópolis: Núcleo de Publicações CED/UFSC, 2012. p. 63-79.

SOUZA, R. J. de. et al. Ler e compreender: estratégias de leitura. Campinas: Mercado das Letras, 2010.

SUDWEEKS, R. R.; GLISSMEYER, C. B.; MORRISON, T. G.; WILCONX, B. R.; TANNER, M. W. Establishing reliable procedures for rating ELL students' Reading comprehension using oral retellings. Reading Research and Instruction, 43(2), p. 65 86. 2004.

WEAVER, C. A., III; KINTSCH, W. Expository text. In: BARR, R.; KAMIL, M. L.; MOSENTHAL, P.; PEARSON, P. D. (orgs.). Handbook of reading research. White Plains, NY: Longman, vol. 2, p. 230-244, 1991.

WESTBY, C. The effects of culture on genre, structure, and style of oral and written texts. In: WALLACH, G. P.; BUTLER, K. G. (orgs.) Language learning disabilities inschool-age children and adolescents. New York: Merrill, p. 180-218, 1994.

WILLIAMS, J. P. Instruction in reading comprehension for primary-grade students: A focus on text structure. The Journal of Special Education, 39(1), p. 6-18, 2005. 